\title{
Perspectives of Silicone Elastomere Implants Use in Preventing Postoperative Complications in Pelvic Exenteration for Advanced Cancers
}

\author{
GEORGE JINESCU ${ }^{1 *}$, NICOLAE BACALBASA ${ }^{2}$, ANDRA EVTODIEV ${ }^{3}$, IULIA-ADELINA MARIN ${ }^{3}$, \\ IOANA CHIULAN ${ }^{4}$, ELENA-RUXANDRA RADU ${ }^{4}$, ADRIANA NICOLETA FRONE ${ }^{4}$, RUXANDRA COSTEA $^{5}$, \\ STEFANIA RAITA ${ }^{5}$ \\ ${ }^{1}$ Carol Davila University of Medicine and Pharmacy in Bucharest, Department of Surgery, 37 Dionisie Lupu, 020022, \\ Bucharest, Romania, Clinical Emergency Hospial Bucharest, 8 Calea Floreasca, 014461, Bucharest, Romania \\ ${ }^{2}$ Carol Davila University of Medicne and Pharmacy in Bucharest, Department of Obstetrics and Gynecology, \\ 37 Dionisie Lupu, 0200022, Bucharest, Romania \\ ${ }^{3}$ Clinical Emergency Hospial Bucharest, 8 Calea Floreasca, 014461, Bucharest, Romania \\ ${ }^{4}$ ICECHIM, 202 Splaiul Independentei, 060021, Bucharest, Romania \\ ${ }^{5}$ University of Agronomic Sciences and Veterinary Medicine of Bucharest, 105 Splaiul Independentei, 050097, \\ Bucharest, Romania
}

\begin{abstract}
In this work, silicone elastomer films with potential to be used as implantable pelvic prosthesis were prepared and their bioactivity was studied both in vitro and in vivo environment. Tensile tests, hardness measurement and compression analysis revealed no significant decrease of the mechanical performance after in vitro hydrolytic degradation in simulated body fluids. The in vivo biocompatibility of films was assessed by implanting them subcutaneously in swine model, for 30 days. Their mechanical characteristics were similar to those of samples immersed in simulated body fluids, for the same time interval. No sign of fibrosis or necrosis were detected from the histological analysis performed on the tissue surrounding the films. In combination, these results indicate that this material has a very good resistance to mechanical and chemical fatigue, do not release any toxic degradation products and, therefore, has great potential as to be used further for preparation of pelvic prosthesis.
\end{abstract}

Keywords: pelvic exenteration, silicone elastomer, biocompatibility, in vivo, intestinal obstruction

The incidence of cancer is growing worldwide, and the number of oncological surgeries, including pelvic exenteration for advanced tumors is increasing. Pelvic exenteration is an extensive surgical technique that involves en bloc resection of the pelvic organs, including the bladder, internal reproductive organs and the rectosigmoid. This procedure aims to cure advanced primary or recurrent cancers confined to the pelvis. It is indicated in gynecologic tumors (cervical, uterine, vulvar), urologic and colorectal cancers. Pelvic exenteration is a radical, major surgery and is therefore associated with significant morbidity and mortality [1,2].

Complication rate has been reported as high as $40-50 \%$ for severe complications and about $80 \%$ for minor events [1]. Local complications are favored by the remaining empty space in the exenterated pelvis in which intraabdominal organs can migrate, especially small bowel loops. They include infections, pelvic collections, anastomotic leaks or fistulae, adhesions, bowel obstruction, urinary obstruction, wound complications etc. General complications include thromboembolic disease, pneumonia, atelectasis etc. [1-3]. Perioperative mortality has been reported between 3 and $5 \%[1]$.

Current surgical techniques that aim to reduce the remaining space consist of importing healthy tissues into the exenterated pelvis [3]. Examples of such techniques are omental flaps [1], local advancement, rotation flaps and pedicled musculocutaneous flaps that use the rectus abdominis, the gluteal or the gracilis muscles [3].

As an alternative to these techniques, a synthetic prosthesis that can be implanted in the remaining empty pelvic cavity in human subjects, following pelvic exenteration is proposed.

Silicone elastomers are used for a wide range of applications from different daily goods, sealants and additives in construction industry, in textile and automotive industries, but also for medical applications. They possess good chemical and thermal stability, excellent weatherability and electrical insulation properties. In the medical field, they provide several advantages, such as high elasticity, low toxicity, biocompatibility and hydrophobicity, thus inhibiting cell adherence [4]. Nowadays, silicone elastomers are used predominantly in breast surgery, as mammary implants for aesthetic purposes or following mastectomy for breast cancer. Other medical applications include orthopedic and maxillofacial prostheses, valves and stents, cardiopulmonary bypass equipment, soft tissue replacement, catheters and canulae [5-7]. Inside the peritoneal cavity, silicone elastomers are extensively used in the form of drainage tubes inserted in order to prevent intraabdominal fluid collections [8]. To the best of our knowledge, no study concerning the use of silicone elastomers as long term intraperitoneal implants has been reported in literature up to now.

*email: gjinescu@yahoo.com 
The most important properties of the ideal prosthetic material are biological inertness and biocompatibility. The simplest way to study the biocompatibility is through in vitro methods, using simulated body fluids, which contain the same inorganic ions and in the same concentration that are naturally found in the blood plasma [9]. However, according to some authors the obtained results do not always match those obtained using living tissues or organisms, therefore in vivo testing is mandatory.

In vivo implantation of biomaterials currently available can be associated with complications, which can be infectious or non-infectious. Infectious complications are caused by contamination of the implant with bacteria. Microorganisms adhere and proliferate on the surface of the biomaterial and in some cases, they can produce biofilms, which increase resistance to antibiotics and to the host's immune system. The most common causative agent is Staphylococcus spp, especially Staphylococcus aureus [10, 11].

Non-infectious complications are caused by local inflammatory reactions (foreign body reaction) or by implant failure. Foreign body reactions can manifest as granuloma, fibrosis, calcification, thrombosis and adherence to the bowel, which can lead to intestinal obstruction, bowel perforation and fistulae [11,12]. Implant failure manifests as rupture of the silicone implant and is associated with the degradation process. It is attributed to different factors, such as weakening of polymer network due to penetration of lipids, immune response to microorganisms colonizing the implant and mechanical fatigue caused by the body movements $[13,14]$.

Moreover, the mechanical resistance of the prosthesis can be affected by the microorganisms present in the implant, by the lipids penetrating into the polymer network, or local fatigue degradation due to daily movements [1315]. Therefore, the purpose of this work was to characterize from the point of view of mechanical and biological features a commercial material considered suitable to be used for the pelvic prosthesis.

The silicone films were processed and evaluated regarding the in vivo biocompatibility and the mechanical properties of films made of a commercial silicone rubber, intended to be used further in the development of new prosthesis, that can fill the empty pelvic cavity following pelvic exenteration, thus preventing postoperative complications. Moreover, a comparative analysis between the impact of both in vitro and in vivo conditions on the mechanical properties, is provided.

\section{Experimental part}

\section{Material and methods}

A mixture of equal parts A and B of silicone Elastosil LR 3003/40 (Wacker Chemie, Germany) were added in a laboratory mixer and consistently mixed for $1 \mathrm{~h}$. To prepare the silicone films, about $55 \mathrm{~g}$ of the mixture was added in a $15 \times 15 \times 0.2 \mathrm{~cm}$ metal frame and crosslinked into a Dr. Collin laboratory press, in the following conditions: $165^{\circ} \mathrm{C}$, $50 \mathrm{~atm}$, for 5 minutes. For post-crosslinking, the pressed samples were placed in the oven at $200^{\circ} \mathrm{C}$ for 4 hours. The obtained sample was denoted as " $\mathrm{S}_{0}$ ". A schematic illustration of the fabrication process is depicted in figure 1.

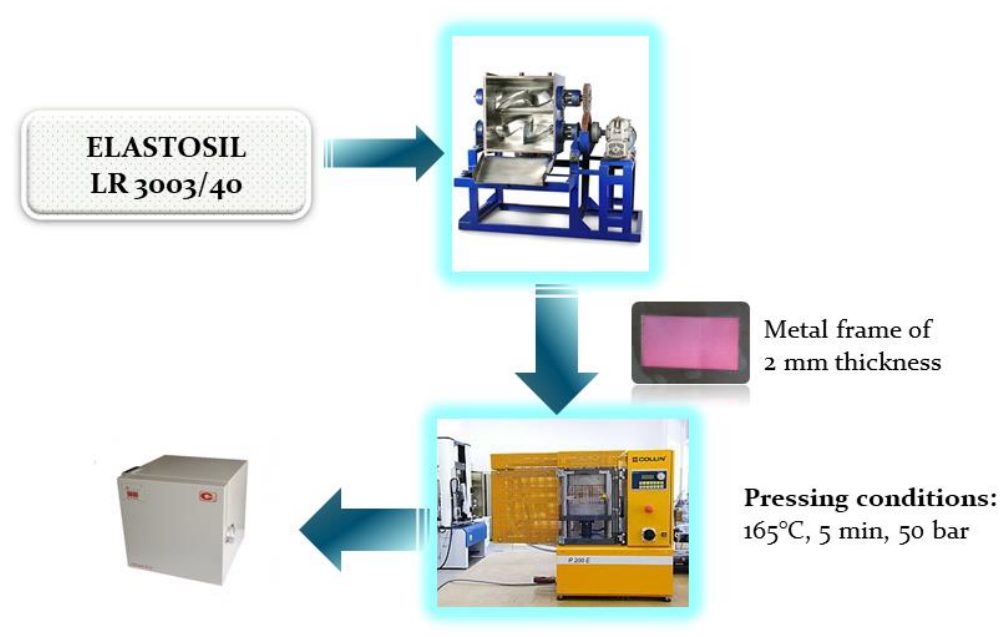

Fig 1. Schematic representation of the film fabrication

The in vitro study of bioactivity was performed by immersion of the samples in a saline solution, "simulated body fluids", widely accepted in literature to assess the biocompatibility of an artificial material. A disk with $5 \mathrm{~cm}$ in diameter was cut from the pressed film and soaked in $200 \mathrm{ml} \mathrm{SBF}$ solution under static conditions, at $37^{\circ} \mathrm{C}$, in filledup and hermetically sealed $500 \mathrm{~mL}$ glass vials, for one month. The SBF was prepared as reported in literature and the composition is given in table $1[16,17]$. The obtained sample was denoted as " $\mathrm{S}_{\mathrm{SBF}}$ ". 
Table 1

CHEMICAL COMPOSITION OF THE PREPARED SIMULATED BODY FLUID

\begin{tabular}{|ccc|}
\hline Nr. crt. & Reactive & Quantity \\
\hline $\mathbf{1}$ & $\mathrm{NaCl}$ & $7.996 \mathrm{~g}$ \\
$\mathbf{2}$ & $\mathrm{NaHCO}_{3}$ & $0.350 \mathrm{~g}$ \\
$\mathbf{3}$ & $\mathrm{KCl}$ & $0.224 \mathrm{~g}$ \\
\hline $\mathbf{4}$ & $\mathrm{K}_{2} \mathrm{HPO}_{4} \cdot 3 \mathrm{H}_{2} \mathrm{O}$ & $0.228 \mathrm{~g}$ \\
$\mathbf{5}$ & $\mathrm{MgCl}_{2} \cdot 6 \mathrm{H}_{2} \mathrm{O}$ & $0.305 \mathrm{~g}$ \\
$\mathbf{6}$ & $1 \mathrm{M}-\mathrm{HCl}$ & $40 \mathrm{~mL}$ \\
$\mathbf{7}$ & $\mathrm{CaCl}_{2}$ & $0.278 \mathrm{~g}$ \\
$\mathbf{8}$ & $\mathrm{Na}_{2} \mathrm{SO}_{4}$ & $0.071 \mathrm{~g}$ \\
$\mathbf{9}$ & $\left(\mathrm{CH}_{2} \mathrm{OH}\right)_{3} \mathrm{CNH}_{2}$ & $6.057 \mathrm{~g}$ \\
\hline
\end{tabular}

The tensile properties were evaluated in static regime, according on SR ISO 37 standard, using an Instron testing machine (model 3382). Five specimens, type 2, stamped from each sample, were tested until fracture, using a $1 \mathrm{kN}$ cell, using a crosshead speed of $200 \mathrm{~mm} / \mathrm{min}$. The measurements were performed at room temperature, on unconditioned specimens. Mean and standard deviation were automatically calculated for all the samples.

Dynamic mechanical analysis of the samples was carried out on a DMA Q800 V20.24 instrument. Measurements were made on a compression mode, at a constant temperature of $30^{\circ} \mathrm{C}$, on $4 \mathrm{~mm} \times 10 \mathrm{~mm}$ specimens, using repeating steps of 3 min isothermal period and compression, with a force increasing with $0.5 \mathrm{~N}$ up to $18 \mathrm{~N}$.

Hardness tests were conducted according to SR EN ISO 868/2003. The samples were cut into squares of $4 \mathrm{~cm} \mathrm{x} 4$ $\mathrm{cm}$ and tested with a Shore A Zwick tester. Five readings were recorded for each sample and the results were averaged.

In vivo tests were performed on swine, which represent the ideal animal model, because of the similarities with humans form the anatomical and physiological point of view. Two male pigs were chosen by a veterinarian, aged 4 months, with an average weight of $19.7 \mathrm{~kg}$.

In order to test the biocompatibility of the prosthesis, it was first sterilized according to standard procedures. It was then introduced in the peritoneal cavity of the swine, under conditions of asepsy, antisepsy, anesthesia and analgesia. Four weeks postoperatively, the prosthesis was extracted from the peritoneal cavity. The response of the live tissues in contact with the prosthesis was evaluated using comparative histopathological examinations from peritoneal samples before and after implantation. (fig. 2).

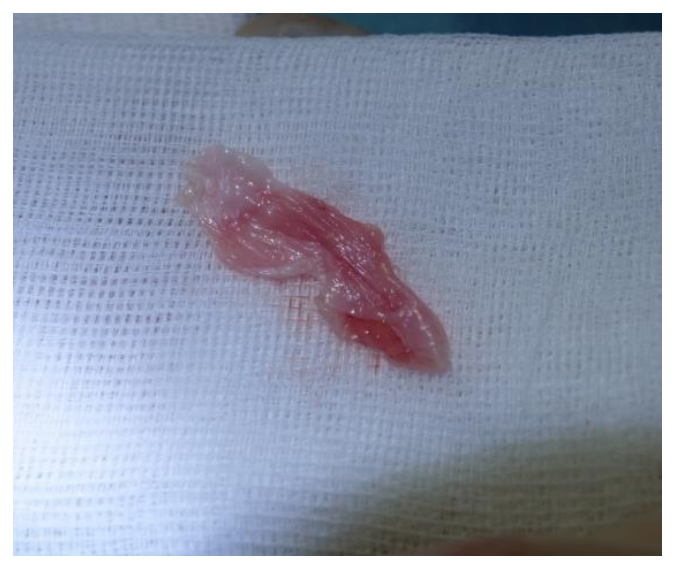

Fig 2. Photographic image of peritoneum sample

\section{Operative technique}

Preoperative preparation consisted in fasting for 8 hours prior to surgery, skin preparation with antiseptic solutions (povidone-iodine 10\%) and sterile drapes in order to prepare the operating field. Preanesthetic medication (Ketamine $20 \mathrm{mg} / \mathrm{kg}$ and Xylazine $2 \mathrm{mg} / \mathrm{kg}$ ) was administered intramuscularly. After 10-12 minutes, venous access was established and induction of anesthesia was performed, using Propofol $1.5 \mathrm{mg} / \mathrm{kg}$. Anesthesia was maintained with Ketamine $1.5 \mathrm{mg} / \mathrm{gk}$ and Lidocaine $2 \mathrm{mg} / \mathrm{kg} / \mathrm{h}$ administered intravenously. Local anesthesia was also used, through subcutaneous infiltration at the incision site of Lidocaine $1 \% 2 \mathrm{mg} / \mathrm{kg}$.

During the surgical procedure there was continuous monitoring of vital signs (cardiac frequency, systemic blood pressure, respiratory frequency, pulseoximetry, body temperature), anesthesia depth and muscle relaxation. The animal subjects were administered oxygen ( $100 \%$ concentration) and crystalloid fluids in continuous intravenous infusion $(\mathrm{NaCl} 5 \% 5 \mathrm{ml} / \mathrm{kg} / \mathrm{h})$.

The in vivo implantation of the silicone elastomer film in the peritoneal cavity of the two animal models was achieved in a surgical procedure. In both subjects, a $10 \mathrm{~cm}$ skin incision was performed along the midline, in the upper abdomen of the swine. Next, the subcutaneous tissues were dissected, the musculo-aponeurotic plane was identified and divided, exposing the underlying parietal peritoneum. The peritoneum was incised and the peritoneal cavity was 
accessed. As well as that, a fragment of parietal peritoneum with a diameter of $1 \times 2 \mathrm{~cm}$ was sampled for histopathological examination.

The peritoneal cavity was explored before the implantation of the silicone elastomer film. Each film was inserted in the peritoneal cavity of an animal subject, in contact with intraabdominal organs, especially small bowel loops. The film was secured to the abdominal wall using 2-0 non-resorbable polypropylene sutures. Six interrupted, horizontal mattress ("U" - shaped) sutures were used to anchor the film to the peritoneum and the musculo-aponeurotic structures.

After the implantation, the abdominal wall was closed, using multifilament resorbable running sutures for the musculo-aponeurotic plane. The skin was closed using a subcuticular suture.

Four weeks postoperatively, the two swine were reoperated, in order to extract the film from the peritoneal cavity. An iterative midline incision was performed, followed by subcutaneous tissues dissection and division of the musculoaponeurotic plane. The parietal peritoneum was identified and a mild thickening was noticed. A 1 x $2 \mathrm{~cm}$ sample of parietal peritoneum was taken for histopathological examination. The peritoneal cavity was accessed and thoroughly explored, in order to identify the position and aspect of the film, its relation to surrounding live tissues and any macroscopic changes of the intraabdominal organs. The film was extracted from the peritoneal cavity after the anchoring polypropylene sutures were removed (the sample is denoted as $\mathbf{S}_{\mathrm{pigs}}$ ). The abdominal wall was closed using resorbable running sutures.

The response of the living tissues and organs of the animal model in contact with the silicone elastomer film was evaluated using macroscopic intraoperative findings and microscopic histopathological examination. Intraoperatively, the organs inside the peritoneal cavity were examined visually and using palpation, looking for inflammatory changes secondary to exposure to the film. The presence of adhesions (involving small or large bowel loops, the parietal peritoneum, the omentum or the film), visceral lesions or free intraabdominal fluid were noted. Histopathological examination evaluated the presence of foreign body inflammatory reaction in the parietal peritoneum in contact with the implanted films. On microscopic examination, indication of inflammatory reactions were considered: inflammatory cells such as lymphocytes or granulocytes, giant foreign body cells, hystiocytes, erosion of the mezothelial layer of the peritoneum, microvascular congestion, thrombosis, perivascular extravasation of red blood cells, granuloma, fibrosis, calcification and necrosis.

\section{Results and discussions}

The failure of silicone implants is attributed to different factors, such as weakening of polymer network due to penetration of lipids and mechanical fatigue caused by the body movements [13,14]. In a previous work, we proved that Elastosil LR 3003/40 can be considered a material of choice for the development of pelvic prosthesis, from the point of view of mechanical strength, even without reinforcing [18]. Preliminary in vitro biological tests made on L929 fibroblasts mouse cells showed a good short-time cytocompatibility, while the measurement of the cytokine secretion revealed no inflammatory response [18]. In this study we focused on the host tissue response in contact with films made of neat silicone elastomer and the ability of this material to keep its mechanical performance in a living organism.

\section{Intraoperative findings}

In the first phase of experiment, the peritoneal cavity of the swine, before implantation of the silicone elastomer film, showed no pathological elements or anatomical variations in either of the animal subjects. In the second phase of the in vivo test, during the surgical intervention, several elements were noted, regarding the presence of the implanted films or concerning the appearance of adhesions between the omentum and the abdominal wall or the presence of serous fluid inside the peritoneal cavity.

The implants were found in their normal position, well anchored to the abdominal wall. They presented no changes in shape or size. Explantation was performed easily, without incidents, by dividing the polypropylene sutures.

The location of the adhesions was at the site of the incision, between the greater omentum and the abdominal wall (fig. 3). They were minimal, loose and did not obstruct neighboring organs (small bowel loops). They were easily divided and normal anatomy was restored. The exploration of the peritoneal cavities did not reveal any adhesions involving the intestinal loops or the implanted silicone elastomer. No lesions of intraabdominal organs were found.

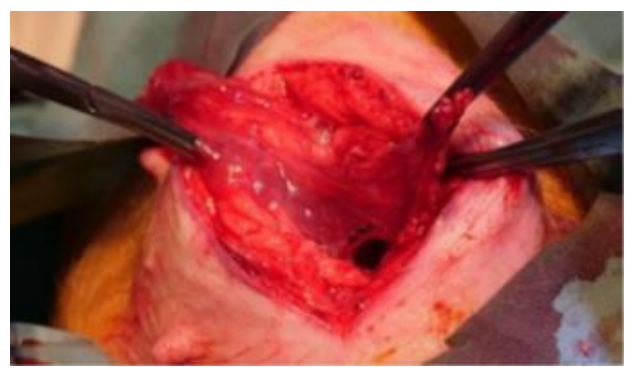

Fig 3. Photographic image of intraoperative aspect of adherences between the omentum and the abdominal wall 
These were not interpreted as a foreign body reaction to the implanted silicone elastomer. The formation of adherences is a well-known and recognized phenomenon following laparotomies and therefore has been attributed to the surgical intervention itself, rather than the implantation of the silicone elastomer.

\section{Hystopathological examination}

Microscopic examination of the parietal peritoneum sampled before implantation revealed no pathological elements. The peritoneum was intact and its constituent layers, the mesothelial layer and the underlying connective tissue, were visible on examination.

The parietal peritoneum sampled from the two animal models after being in contact with the silicone elastomer film for 4 weeks presented the following changes: i) erosion of the mesothelial layer, ii) the presence of inflammatory cells and iii) changes in the microcirculation.

The most common cellular types were lymphocytes. Rarely, some granulocytes and giant foreign body cells were observed (fig. 4).

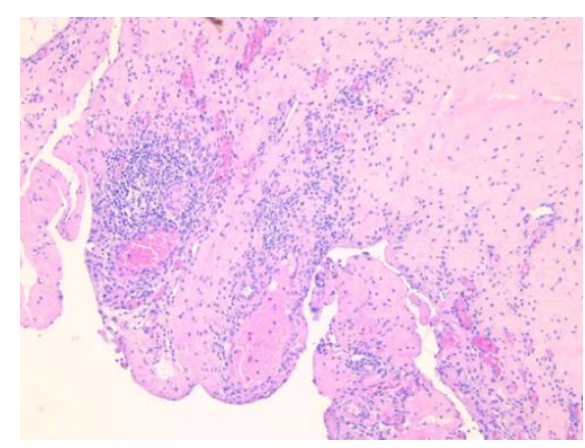

Fig 4. Microscopic aspect showing inflammatory cells (lymphocytes, granulocytes and foreign body cells)

The small vessels in the peritoneal connective tissue showed congestion, microthromboses and extravasation of red blood cells in the perivascular tissues.

The inflammatory reaction observed on microscopic examination was minimal. No signs of necrosis, granulomas, fibrosis or calcification were noted on histopathological examination.

These findings are consistent with host reactions documented in the literature, in response to surgical implantation of biomaterials commonly used nowadays in the medical field, such as silicone, polypropylene, ePTFE etc. [19].

\section{Mechanical characterization}

The unaged sample and the samples subjected to in vitro and in vivo studies were mechanically tested in order to assess the impact of the saline environment or the complex biochemical system found in an animal model on the material strength. The results recorded during the tensile tests are plotted together with those obtained for the unaged sample, as shown in figure 5. The maximum stress at the break point exhibited an increase with $9.8 \%$ and $11.6 \%$ as results of immersion in SBF or implantation in pigs, as compared with the sample before any aging conditions, which indicates an increased stiffness. This result is in agreement with our previous study [18], where the elastomers subjected to intensive stress fatigue generated mechanically by means of a flexometer, exhibited an increase with $12.4 \%$ of the tensile strength after 1 million cycles. In this case, the increase of tensile strength after simulated and in vivo tests may be due to a surface mineralization [20]. Figure 5 (a) shows a negligible decrease of the elongation at break after both in vitro and in vivo studies, from $948 \%$ in the case of sample $\mathrm{S}_{0}$ to $935 \%$ and $929 \%$ for the samples $\mathrm{S}_{\mathrm{SBF}}$ and $\mathrm{S}_{\mathrm{pigs}}$, respectively. All these results suggest that the presence of water and saline environment will not compromise the integrity of the pelvic prosthesis.

The tensile tests results are sustained by the hardness values (table 2), which indicates a slight decrease of the surface flexibility as consequence of biological environment. It is worth mentioning the minor differences between the in vitro and in vivo degradation results, although higher differences between the two biological tests were reported by several authors [21-23].

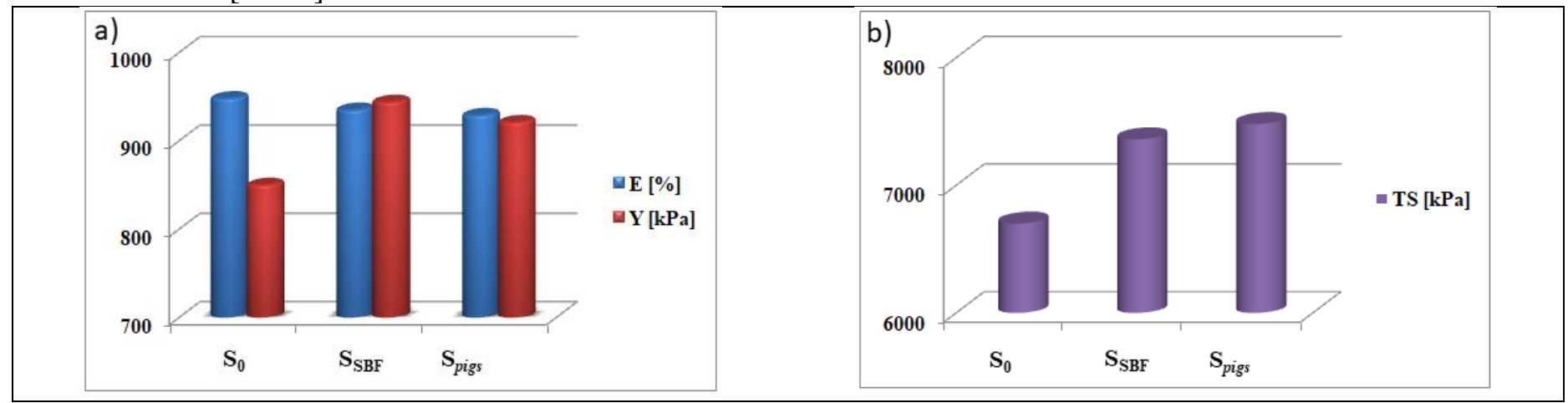

Fig 5. a) Mechanical properties (TS - tensile strength, E - elongation at break, Y - Young modulus) of the unaged sample ( $\left.\mathrm{S}_{0}\right)$, and samples subjected to in vitro $\left(\mathrm{S}_{\mathrm{SBF}}\right)$ and in vivo $\left(\mathrm{S}_{\mathrm{pigs}}\right)$ studies 
Table 2

SHORE A HARDNESS VALUES

\begin{tabular}{|c|c|c|c|}
\hline Sample name & $\mathrm{S}_{0}$ & $\mathrm{~S}_{\mathrm{SBF}}$ & $\mathrm{S}_{\text {pigs }}$ \\
\hline Hardness & 43.0 & 47.7 & 45 \\
\hline
\end{tabular}

The tensile and hardness results are supported by DMA compression test (fig. 6). A slight decrease of flexibility illustrated by the decrease of strain for a particular stress was observed after the biological tests.

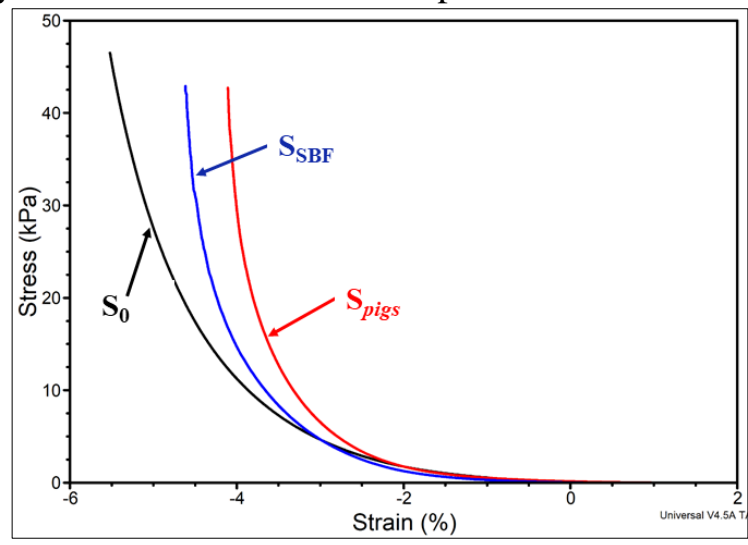

Fig 6. Compression tests on the original sample $\left(\mathrm{S}_{0}\right)$, after immersion in $\mathrm{SBF}(\mathrm{SSBF})$ and after in vivo study $\left(\mathrm{S}_{\mathrm{pigs}}\right)$

\section{Conclusions}

The in vivo study was performed on pigs as experimental model and the implanted silicone films were mechanically tested and compared with samples immersed in saline solution (SBF) for the same period of time. Results showed a good correlation between the in vitro and in vivo studies, reflected in similar values of the mechanical parameters. The stiffening effects was negligible in both aging conditions, which demonstrate that the selected material is suitable for implants and prosthesis.

The intraoperative aspects observed during in vivo tests on swine, which showed loose adhesions, as well as the histopathological examination, that demonstrated a minimal inflammatory response, suggest that silicone elastomers could be safely implanted long term inside the peritoneal cavity.

Acknowledgment: This work was supported by a grant of the Romanian National Authority for Scientific Research and Innovation, CCCDI UEFISCDI, project number COFUND-MANUNET III-MedIn-1, within PNCDI III, contract no. 33/2018 and contract no. $35 / 2018$.

\section{References}

1.DIVER, E.J., RAUH-HAIN, J.A., DEL CARMEN, M.G., Int. J. Surg. Oncol., 2012, 2012, p. 1

2.WYDRA, D., EMERICH, J., SAWICKI, S., CIACH, K., MARCINIAK, A., World J Gastroenterol., 12, no. 7, 2006 , p. 1115.

3.DAVIES, M.L., HARRIS, D., DAVIES, M., LUCAS, M., DREW, P., BEYNON, J., Int. J. Surg. Oncol., 2011, 2011, p. 1.

4.RANELlA, A., BARBELOGLOU, M., BAKOGIANNI, S. , FOTAKIS, C., STRATAKIS, E., Acta Biomaterialia, 6, no. 7, 2010 , p. 2711.

5.CHEN, Q., LIANG, S., THOUAS, G., A., Prog. Polym. Sci., 38, no. 3-4. 2013, p. 584.

6.KHAN, W., MUNTiMAdugu, E., JAFFE, M., DOMB, A.J., Focal Controlled Drug Delivery, 1, Springer US, Domb A., Khan W., Boston, MA, 2014, p. 33.

7.HU, X., PAN, X., JOHNSTON, J., M., J. Prosthet. Dent., 112, no. 5, 2014, p. 1298.

8.NOMURA, T., SHIRAI, Y., OKAMOTO, H., HATAKEYAMA, K., Surg. Today., 28, no. 9, 1998, p. 940.

9.ENIKÓ, G., ISTVÁN, F., ISTVÁN, L., J. Compos. Sci., 1, 15, 2017, p. 1.

10.NARKHEDE, R., SHAH, N.M., DALAL, P.R., MANGUKIA, C., DHOLARIA, S., Indian J. Surg., 77, no. 4, 2015 , p. 322.

11.JINESCU, G., MARIN, I.A., EVTODIEV, A., CHIDIOȘAN, C., Polypropylene "in vivo" implantation in inguinal hernia repair - adverse reactions, Rev. Chim. (Bucharest), 70, no. 12, 2019, p. 4508.

12.KALABA, S., GERGARD, E., WINDER, J.S., PAULI, E.M., HALUCK, R.S., YANG, J., Bioact. Mater., 1, no. 1, 2016 , p. 2.

13.SCHUBERT, D.W., LÄMMLEIN, M., VON HANSTEIN, H., Polym. Test., 66, 2018, p. 292.

14.NECCHI, S., MOLINA, D., TURRI, S., ROSSETTO, F., RIETJENS, M., PENNETI, G., J. Mec. Behav. Biomed., 4, no. 8, 2011 , p. 2002.

15.MOJSIEWICZ-PIENKOWSK, K., KRENCZKOWKA, D., Chemosphere, 191, 2018, p. 204.

16.KOKUBO, T., KUSHITANI, H., SAKKA, S., KITSUGI, T., YAMAMURO, T., Solutions able to reproduce in vivo surface-structure changes in bioactive glass-ceramic A-W, J. Biomed. Mater. Res., 24, 721-734,1990

17.KOKUBO, T., TAKADAMA, H., Biomaterials, 27, no. 15, 2006, p. 2907.

18.CHIULAN, I., PANAITESCU, D.M., RADU, E.R., FRONE, A.N., GABOR, R.A., NICOLAE, C.A., JINESCU, G., TOFAN, V., CHINGACARRASCO, G., J. Mech. Behav. Biomed., 101, 2020, p. 103427.

19.IBRAHIM, M., BOND, J., MEDINA, M.A., CHEN, L., QUILES, C., KOKOSIS, G., BASHIROV, L., KLITZMAN, B., LEVINSON, H., Eur. J. Plast. Surg., 40, no. 5, 2017, p. 383.

20.SMITH, L.J., DEYMIER, A.C., BOYLE, J.J., LI, Z., LINDERMAN, S.W., PASTERIS, J.D., XIA, Younan, GENIN, G.M., THOMOPOULOS, S., Interface Focus, 6, no. 1, 2015, p. 70.

21.TOWLER, M.R., Boyd, D., Freeman, C., Brook, I.M., Farthing, P., J. Biomater. Appl., 23, no. 6, 2009, p. 561.

22.WU, C., ZHANG, Y., FAN,W., KE, X., HU, X., ZHOU, Y., XIAO, Y., J. Biomed. Mater. Res. A, 98, no. 1, 2011 , p. 122.

23.ABOU NEEL, E.A., MIZOGUCHI, T.; ITO, M., BITAR, M., SALIH, V., KNOWLES, J.C., Biomaterials, 28, no. 19, 2007 , p. 2967.

Manuscript received: 30.12.2019 
